\title{
Exploring the diversity and ecology of testate amoebae in West Siberian peatlands
}

\author{
Yuri MAZEI I, , Viktor CHERNYSHOV ${ }^{\mathrm{b}}$, Sergei BUKHKALO ${ }^{\mathrm{c}}$, Natalia MAZEI ${ }^{\mathrm{a}, \mathrm{d}}$, Angela \\ L. CREEVY', Richard PAYNE ${ }^{\mathrm{b}, \mathrm{f}}$ \\ ${ }^{a}$ Lomonosov Moscow State University, Moscow, Russia; ${ }^{b}$ Penza State University, Penza, Russia; ${ }^{\mathrm{c}}$ Tobolsk Complex Scientific

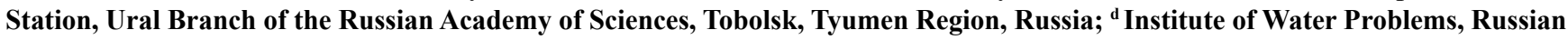 \\ Academy of Sciences, Moscow, Russia; ${ }^{\mathrm{e}}$ Geography, Edge Hill University, Ormskirk, United Kingdom; ${ }^{\mathrm{f}}$ Environmental Geography, \\ University of York, Heslington, United Kingdom
}

\begin{abstract}
Testate amoebae are valued for their functional significance and application as indicators of environmental conditions, particularly in peatland ecosystems. Research on testate amoebae has increased dramatically in recent years but there are still large parts of the world which have seen very little research. Here we consider testate amoeba communities of the West Siberian Lowland, the world's largest peatland region and therefore one of the largest potential habitats for testate amoebae. Extensive sampling identified 89 taxa and showed that testate amoeba communities are structured by their physical and biological environment. We identified significant relationships between amoeba communities and both moisture content and vegetation composition. Despite the assemblages containing many widely-distributed species, some taxa considered typical of peatlands (e.g. Archerella flavum and Hyalosphenia papilio) were comparatively rare or absent, paralleling findings further south in Asia. We suggest that testate amoebae in this region deserve further study and may have useful applications in palaeoecological reconstruction and as bioindicators of the impacts of oil and gas extraction.
\end{abstract}

Key words: Testate amoebae, protist; Western Siberia, diversity, ecology, wetland, mire

\section{INTRODUCTION}

Testate amoebae (TA) are a diverse and abundant group of protists found in a wide range of habitats around the world and are particularly abundant in wetlands (Mitchell et al. 2008). TA researchers are accustomed to bemoaning the lack of research on this rela-

Address for correspondence: Richard Payne, Environmental Geography, University of York, Heslington, York YO10 5DD, United Kingdom; E-mail: richard.payne@york.ac.uk tively obscure group of microorganisms, however the number of papers published in the last decade is more than double that published in the preceding three decades combined, while research on other protist groups has remained broadly constant (based on SCOPUS listings: Fig. 1). Whilst the quantity of research on TA is undoubtedly small by the standards of macroscopic organisms, they are rapidly becoming being one of the better-studied groups of protists in many environments. With this increasing volume of research has come an increasing focus on addressing ecological, biogeographic 
and palaeoecological questions at broader spatial scales (Amesbury et al. 2013, Bobrov et al. 2015, Lara et al. 2016). Doing so faces the fundamental problem that we have little knowledge of TA in a large proportion of the globe. The SCOPUS database shows that as a dis-

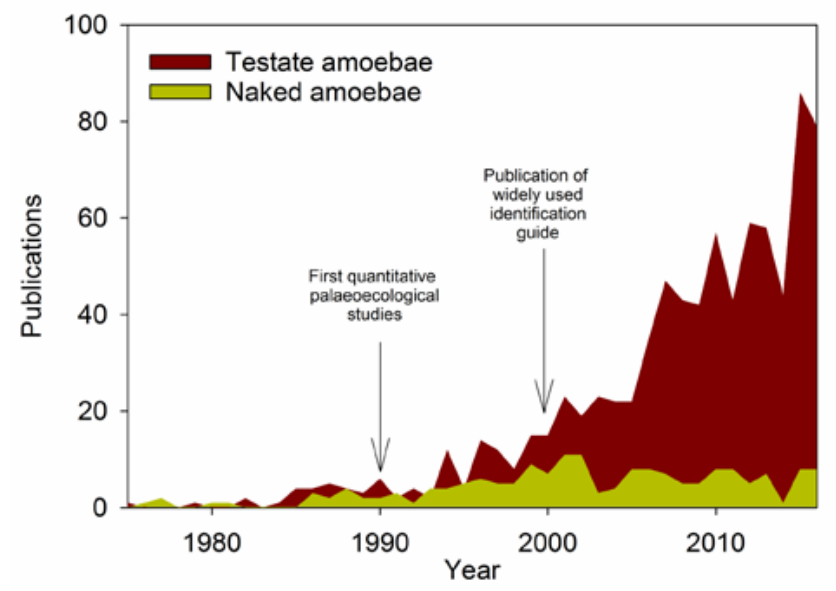

Fig. 1. Trends in publications including the phrase 'testate amoebae' in title, keywords or abstract as determined by a SCOPUS search February 2017. Database publication trends are not necessarily an accurate reflection of quantity of research as not all older material is digitized and there has been a general trend for researchers to publish a greater number of shorter papers. However results are comparable between search terms so it is interesting to note the same data for 'naked amoebae' as a comparison. An important driver of increasing research is palaeoecology and some key events are highlighted for comparison. cipline TA research is heavily skewed, with the majority of researchers based in northern Europe and North America (Fig. 2). This bias may ultimately distort our understanding of the past and present ecology and biogeography of TA.

TA are present in most terrestrial environments, from desert soil crusts (Bamforth 2008) to epilithic mosses (Mazei et al. 2016). However they frequently occur and are particularly abundant in peatlands where they constitute the dominant group of microbial consumers and a large proportion of the total microbial biomass (Gilbert et al. 1998a, b; Jassey et al. 2012). Over the last twenty years peatlands have become the ecosystem most widely investigated for TA. This trend has been particularly driven by increasing interest from palaeoecologists in using the preserved shells of TA as palaeoenvironmental proxies for the reconstruction of long-term change in peatland water table (Charman 1999). To calibrate these records more than thirty studies of modern communities have been undertaken with the aim to produce species-environment models ('transfer functions') to allow palaeoecological data to be interpreted in quantitative terms (Payne et al. 2012a, 2016; Tsyganov et al. 2016). There is now increasing interest in combining these individual studies into larger datasets which can be used to draw broader conclusions (Amesbury et al. 2016, Booth 2008).

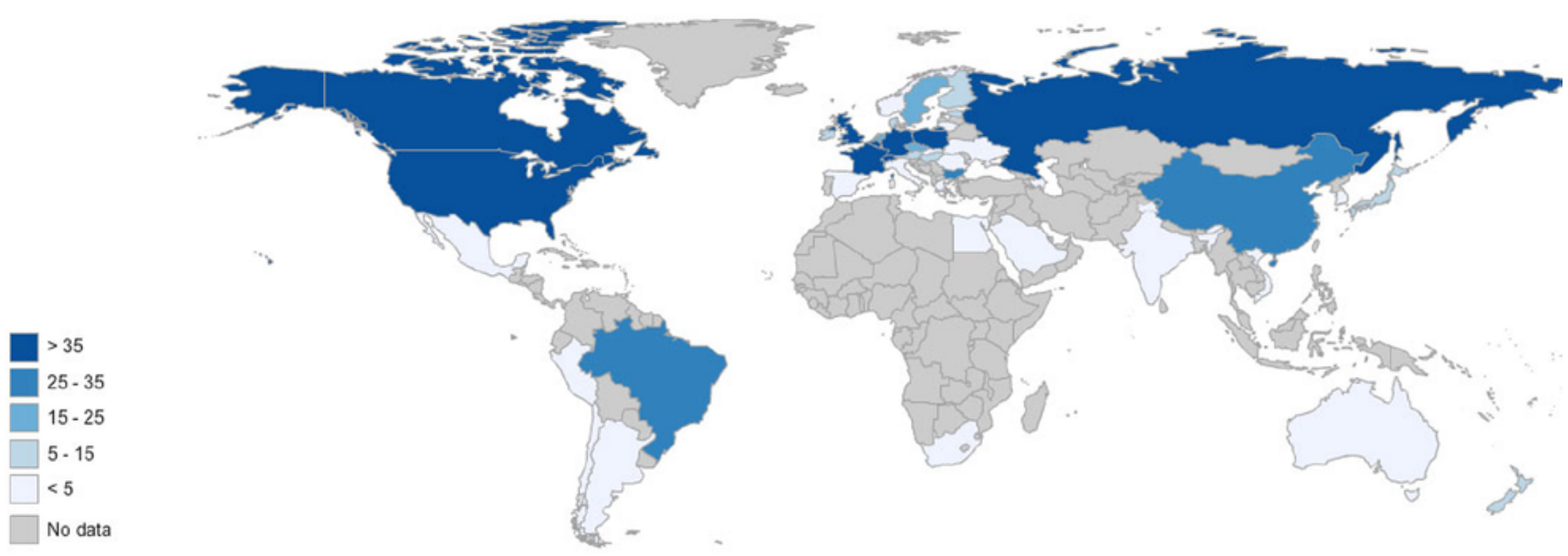

Fig. 2. Author location based on institutional details for 652 publications listed in SCOPUS containing the phrase 'testate amoebae' in keywords, abstract and title. SCOPUS is not a comprehensive source of data on testate amoeba publication (probable biases towards the more recent and English language literature) but provides a reasonable representation of the overall state of the literature. Colour density is proportional to number of publications with grey shading for countries with no identified publications. Map created using the StatSilk mapper tool. 
Peatlands are unevenly distributed around the globe with the largest regions in the boreal zone and particularly in Russia and Canada which collectively contain well over half of global peat (International Peat Society 2017). While both of these countries have a number of research groups actively investigating TA (Fig. 2), research density in relation to spatial extent is still relatively low and biased towards more accessible regions. For instance, the European part of Russia is comparatively well-researched (Bobrov 2003; Mazei 2007a, b, c) compared with Siberia and the Far East which are quite poorly studied. The focus of this paper is TA communities of the West Siberian Lowland (WSL); the large relatively flat plain bounded by the Urals to the west and Yenisei River to the east (Fig. 3). This region is the world's most extensive peatland area containing an estimated $592,440 \mathrm{~km}^{2}$ of peat (Sheng et al. 2004). This represents a non-trivial proportion $(>15 \%)$ of the combined carbon pool of boreal and subarctic peatlands (Gorham 1991). Due to the preferential occurrence of TA in peatlands this region represents one of the largest single potential habitats for TA globally, and yet these communities have been sparsely studied compared to many other regions of the globe.

Published TA studies from the WSL are generally limited-scale, localised and often focussed primarily on major differences in habitat (for example, Rakhleeva (2002), Bokova (2015)). In a study investigating TA in peatlands in the southern Taiga zone Kur'ina (2011) identified 63 taxa and defined water table optima for the taxa. Other studies have found strong links between TA community composition and surface wetness (assessed using vegetation) and distinct communities in different habitats, particularly related to nutrient status (Kur'ina et al. 2010). In the largest recent study, Mazei and Chernyshov (2011) studied 66 samples from two areas of the Tazovskii Peninsula in the far north of Western Siberia, identifying 93 taxa. They found higher abundance and diversity in wet than dry substrates and notable differences in communities between different biotopes. As part of a calibration study for palaeoecological reconstruction Lamentowicz et al. (2015) considered the modern TA communities of a single site near Khanty-Mansiysk and showed links between the community and water table depth. The WSL is comparable in area to Western Europe and it is clear from the literature that the TA assemblages of peatlands across very large areas have yet to be studied at all.
The aims of this contribution are to: i) Explore the abundance, community composition and diversity of testate amoeba communities in six areas of the WSL; ii) Test the influence of soil moisture and vegetation type as key controls on communities; iii) Compare results to other studies; iv) Provide a dataset for regional and supra-regional metaanalyses, planned in subsequent contributions.

\section{MATERIALS AND METHODS}

\section{Study sites}

Fieldwork was conducted at thirteen sites spanning a range of peatland type and geographic positions across the WSL (Fig. 3). Sites were selected within six study areas:

Study area 1: Two sites (Gorno-Slinkino1 and Gorno-Slinkino2) were located in the region of Gorno-Slinkino on the east bank of the Irtysh River in Tyumen Oblast around $58^{\circ} 47^{\prime} \mathrm{N}, 68^{\circ} 47^{\prime} \mathrm{E}$. GornoSlinkino1 is a forested bog ('ryam') with a Pinus sibirica canopy, an understory with shrubs including Ledum palustre and Rubus chamaemorus and a moss layer with Sphagnum species and brown mosses including Pleurozium schreberi, Dicranum spp. and Cladonia lichens. Gorno-Slinkino2 to the southeast of Gorno-Slinkino1 is another forested bog with a Betula canopy, scattered smaller Pinus and shrubs and a moss layer with Hylocomnium splendens, Polytrichum commune and Sphagnum species.

Study area 2: Two sites (Vinokurova1 and Vinokurova2) were located further south in the region of Vinokurova village around $58^{\circ} 18^{\prime} \mathrm{N} 68^{\circ} 20^{\prime} \mathrm{E}$, also on the east bank of the Irtysh. Vinokurova1 had vegetation similar to Gorno-Slinkino2 with a relatively dense Betula canopy overlying shrubs including Ledum palustre, and a moss layer with Polytrichum strictum, Sphagnum species and Cladonia lichens. Vinokurova2 nearby to the east is a more open peatland with scattered Pinus but a vegetation primarily of open Sphagnum with sedges and Andromeda polifolia.

Study area 3: One site (Zapolyarnyi1) was located in the far north of the WSL in the vicinity of Zapolyarnyi village near the eastern bank of the Pur River in the Yamalo-Nenets Autonomous Okrug, around $66^{\circ} 24^{\prime} \mathrm{N} 79^{\circ} 01^{\prime} \mathrm{E}$. The study site is an open tundra peatland with a low vegetation of Sphagnum, Cladonia, Ledum palustre, Betula nana, Oxycoccus palustris and Pleurozium schreberi.

Study area 4: Three sites (Urengoil-3) were located southwest of Zapolyarnyi in the vicinity of the town of Urengoi to the west of the Pur River around $65^{\circ} 35^{\prime} \mathrm{N} 77^{\circ} 35^{\prime} \mathrm{E}$. Urengoil is an open permafrost peatland with Betula nana, Salix, Ledum palustre, Rubus chamaemorus, Sphagnum species and brown mosses including Polytrichum strictum and Polytrichum commune. Urengoi2 is a lake-margin peatland with extensive sedges (particularly Eriophorum spp.), Sphagnum, Andromeda polifolia and Ledum palustre. Urengoi3 is a shrub-dominated peatland with Betula, Salix, sedges, Polytrichum commune and Sphagnum.

Study area 5: One site (Surgut1) was sampled in the middle Taiga zone in the centre of the WSL southwest of the city of Surgut and south of the River $\mathrm{Ob}$ around $60^{\circ} 7^{\prime} \mathrm{N}, 71^{\circ} 30^{\prime} \mathrm{E}$. Surgut1 is 


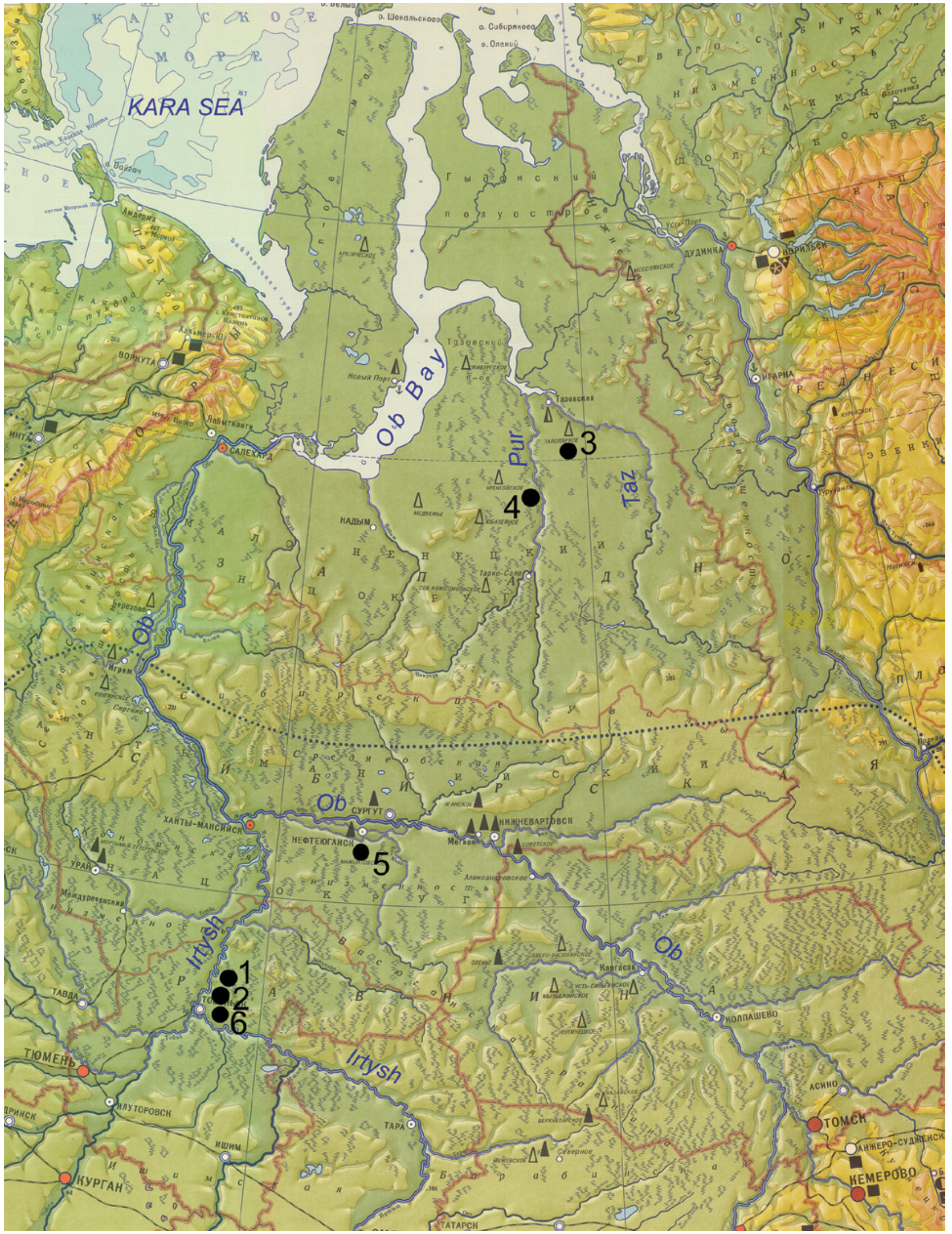

Fig. 3. Geographic position of study areas (1-6) 
a peatland with a scattered cover of Pinus and a shrub-dominated understorey with Ledum palustre, Chamaedaphne calyculata, Rubus chamaemorus and Sphagnum.

Study area 6: Four sites (Tobolsk1-4) were sampled in the vicinity of the town of Tobolsk in the Tyumen Oblast on the east bank of the Irtysh River around 58 $14^{\prime} \mathrm{N} 68^{\circ} 13^{\prime} \mathrm{E}$. Vegetation of Tobolsk1 is of relatively open low 'ryam' forested peatland with scattered Pinus, an extensive shrubby understorey of Ledum palustre with Pleurozium schreberi and sparse Sphagnum. Tobolsk2 is an open sedge-dominated site with an extensive cover of Carex species, Sphagnum including S. papillosum, and scattered Oxycoccus palustris. Tobolsk3 is a sedge-dominated peatland with Carex species, brown mosses, some Sphagnum and scattered Betula trees. Tobolsk4 is an open low 'ryam' peatland with low density Pinus overlying a shrubby understorey with Ledum palustre and Andromeda polifolia.

All studied peatlands are relatively oligotrophic although not all are ombrotrophic. Collectively they span a large part of the variability in peatlands in the WSL including sites with a variety of tree cover density, with and without permafrost and spanning a large geographic region from $58-66^{\circ} \mathrm{N}$ and $68-79^{\circ} \mathrm{E}$. None of these locations have previously been researched for TA. A total of 143 samples were collected and analysed, making this the largest dataset for Western Siberia and one of the larger individual datasets of peatland TA yet produced.

\section{Sampling}

Fieldwork was conducted in the summers of 2008 and 2009. In each site we sampled at 5 to 21 points selected to span the range of habitat types encountered in each study site. Samples of either mosses (where present) or plant litter (where mosses were rare or not present) of approximately $5 \mathrm{~cm}$ depth and $25 \mathrm{~cm}^{3}$ volume were carefully removed and immediately placed in sealed plastic bags to avoid contamination and moisture loss. Samples were refrigerated at $5^{\circ} \mathrm{C}$ as soon as possible and kept refrigerated until preparation and analysis; recent experimental research suggests that this treatment should avoid major post-sampling change in the community structure (Mazei et al. 2015).

\section{Laboratory analyses}

In the laboratory the sample was divided in two. One part was used for the extraction of TA. Samples for TA analysis were prepared using a method based on wet sieving. $1 \mathrm{~cm}^{3}$ of sample was soaked in water for 24 hours, stirred, filtered at $0.5 \mathrm{~mm}$, the suspension left to settle for a further 24 hours, and supernatant decanted off following Mazei et al. (2011). No back-filtering step was used as this leads to the loss of small taxa and a relatively large mesh size $(500 \mu \mathrm{m})$ was used to retain the largest tests (Avel and Pensa 2013, Payne 2009). Samples were examined using a BIOMED-2 microscope and tests identified to a high taxonomic resolution at $400 \times$ magnification using guides including Mazei and Tsyganov (2006). The taxonomic scheme at the genus level is based on the revisions of Dekhtiar (2009) and Kosakyan et al. (2016a, b) as summarized in Tsyganov et al. (2016). All tests were identified and recorded in an aliquot of known volume to allow concentration calculation. This approach yielded variable counts which averaged 102 tests (greater than the cut-off advocated by Payne and Mitchell 2009) but reached as high as 366 tests per sample.
From the second sub-sample we determined moisture content. We weighed the sub-samples wet, placed in an oven at $105^{\circ} \mathrm{C}$ for eight hours, allowed samples to cool in a desiccator and once cooled to room temperature re-weighed. Percentage moisture was calculated from the difference between the pre- and post-oven weights.

\section{Statistical analysis}

We considered two properties of the TA community: the assemblage structure and the diversity. From the TA counts we produced two datasets; one of volumetric test concentration and the second of relative abundance, we used both of these datasets in our analyses. While concentrations have been calculated in many TA ecological studies it has been frequent to only consider percentages in analysis.

To assess variability in community composition between sites and vegetation types we used a non-metric multi-dimensional scaling ordination (Clarke 1993). We calculated Bray-Curtis dissimilarity as a robust and ecologically meaningful measure of compositional dissimilarity (Bray and Curtis 1957). Separate analyses were performed for both relative abundance and concentration. To explore links between the TA community composition and the sampling environment we used redundancy analysis with significance testing by permutation test (999 permutations). The composition data was Hellinger transformed prior to analysis following Legendre and Gallagher (2001). We considered two potential environmental controls on TA communities: soil moisture content and vegetation. Vegetation was not surveyed in detail but was recorded and classified into six broad categories: 'Sedge dominated'; 'Sphagnum-dominated'; 'Brown moss dominated'; 'Lichen dominated'; 'Shrub dominated' and 'Litter covered'. These categories were selected to be broad to maximise the consistency of recording. Categories were based on the dominant plant species so, for instance, many sites recorded as 'shrub dominated' also contained mosses. The 'litter covered' category was included as some sampling locations, particularly in densely forested sites, contained relatively deep accumulations of plant litter with little or no vegetation. We conducted ordinations with both moisture content and vegetation type as constraining variables. We also investigated the abundance of the most frequently occurring species in relation to moisture using Spearman's Rs. As an index of community diversity we calculated the Shannon diversity index H' which incorporates both species richness and evenness (DeJong 1975). We correlated H' with moisture content using Spearman Rs and tested for differences in H' between vegetation types and sites using Kruskal-Wallis tests with Nemenyi post-hoc tests. Data analysis was conducted in $\mathrm{R}$ (R Development Core Team 2014) using packages including vegan (Oksanen et al. 2007) and MASS (Ripley 2016).

\section{RESULTS}

Our dataset contained information for 143 sampling locations and identified 89 testate amoeba species or sub-species representing a total count of 14536 individual tests. Samples contained a mean of 15.7 species with a range of 4 to 28 . The mean test concentration was 134295 ind $\mathrm{cm}^{-3}$ with a range of 562-1195850 
ind $\mathrm{cm}^{-3}$. The most abundant taxon was Trinema lineare, representing a large proportion $(28.8 \%)$ of all tests and particularly abundant in some of the wettest sites. Other abundant taxa included Euglypha laevis (6.4\% tests), Centropyxis aerophila (6.1\%), Corythion dubium (5.9\%) and Assulina muscorum (5.5\%). Eight taxa were represented by just a single test: Arcella megastoma, Awerintzewia cyclostoma, Centropyxis discoides, Euglypha compressa glabra, Nebela marginata, Nebela wailesi, Netzelia wailesi and Plagiopyxis labiata. Two taxa which frequently constitute a large proportion of the testate amoeba community in oligotrophic peatlands: Archerella flavum and Hyalosphenia papilio were surprisingly rare in these samples, representing just 1.2 and $2.1 \%$ of tests respectively. The genus Heleopera was also notably rare $(0.5 \%$ tests $)$ with just a single species identified (H. sphagni). Other common Heleopera species: H. rosea, H. petricola and $H$. sylvatica were not found in these samples. The most abundant taxa are all well-known from peatland studies globally. However some less frequently-recorded taxa deserve comment, including Nebela tenella, Euglypha capsiosa, Ellipsopyxis sp. and Awerintzewia cyclostoma. Given the current fragmented state of testate amoeba taxonomy it is unclear whether these all represent genetically-distinct species but their unusual presence in Western Siberia is notable. A full list of the species identified is presented in Appendix 1.

The NMDS plots (Fig. 4) demonstrate considerable variability in the community composition. Considering the ordination based on relative abundance (Fig. $4 \mathrm{~A})$, there is a clearly visible difference in sample po- sitioning based on moisture content (shown by symbol size) with drier samples (smaller points) having lower scores on axis one and a more subtle tendency for higher scores on axis two. Moisture was significantly correlated $(p=<0.001)$ with both axis one (Spearman $R s=0.76)$ and two $(R s=0.43)$ scores. There were visible differences between sample position in the ordination space by site of origin. While all sites showed considerable variability, it was notable, for instance, that Gorno-Slinkino1 samples tended to have low scores on axis one, Urengoil samples to have high scores on axis two and Tobolsk4 samples to have high scores on axis one. There was a significant difference between sites for scores on both axis one (Kruskal-Wallis $\chi^{2}(12)=63$, $p=<0.001)$ and axis two $\left(\chi^{2}(12)=48, p=<0.001\right)$. There were also significant differences between vegetation types for scores on both axis one $\left(\chi^{2}(5)=19\right.$, $p=0.002)$ and axis two $\left(\chi^{2}(5)=24, p=<0.001\right)$.

The ordination based on test concentration (Fig. $4 \mathrm{~B})$ was notably different from that based on relative abundance. A similar trend towards drier samples having lower axis one scores remained apparent but the positioning of individual sites in the ordination space was different in many respects. This was particularly true on axis two, where for instance Vinokurova2 sites had intermediate to low scores in the relative abundance ordination but high scores in the absolute abundance ordination. Moisture content explained slightly more of the variance in the axis scores for the absolute than relative abundance ordination (NMDS1 $R=0.62$, NMDS2 $R=0.42$, both $p=<0.001$ ). Differences between sites were similarly apparent in the absolute as

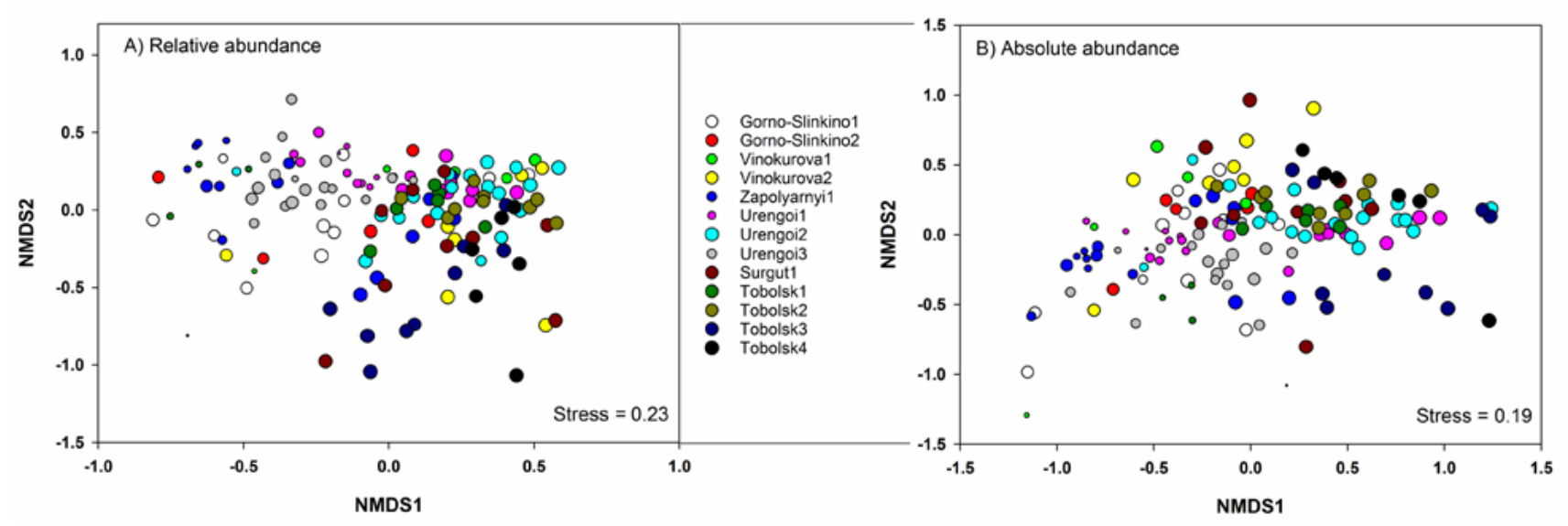

Fig. 4. NMDS ordination of testate amoeba community data based on Bray-Curtis distance. Showing assemblages by site with symbol size proportional to moisture content of sample. Plot A shows data based on relative abundance (percentage) while Plot B shows data based on absolute abundance (concentration). 
the relative abundance results (NMDS1 $\chi^{2}(12)=68$, $p=<0.001$; NMDS2 $\left.\chi^{2}(12)=45, p=<0.001\right)$. There were differences between vegetation types for axis one $\left(\chi^{2}(5)=22, p=<0.001\right)$ but these were not significant for axis two $\left(\chi^{2}(5)=9, p=0.1\right)$.

In constrained ordination, just over a fifth of variance in the testate amoeba data was explained collectively by sample moisture content, vegetation type and site $(21.4 \%, p=0.001)$. The greatest proportion of variance was explained by site, explaining $16.6 \%$ of the variance in the species data with a high level of significance $(p=0.001)$. A smaller proportion of variance was explained by both sample moisture content $(4.8 \%$, $p=0.001)$ and vegetation category $(4.9 \%, p=0.001)$. The RDA plot (Fig. 5) shows the first axis is strongly associated with the moisture gradient. Taxa including Trinema lineare and Hyalosphenia papilio were positively associated with RDA1 and moisture and taxa including Corythion dubium and Nebela tincta were negatively associated. To examine these relationships in more depth we considered correlations between the concentrations of the most abundant species and moisture. In all species there was a generally positive as-

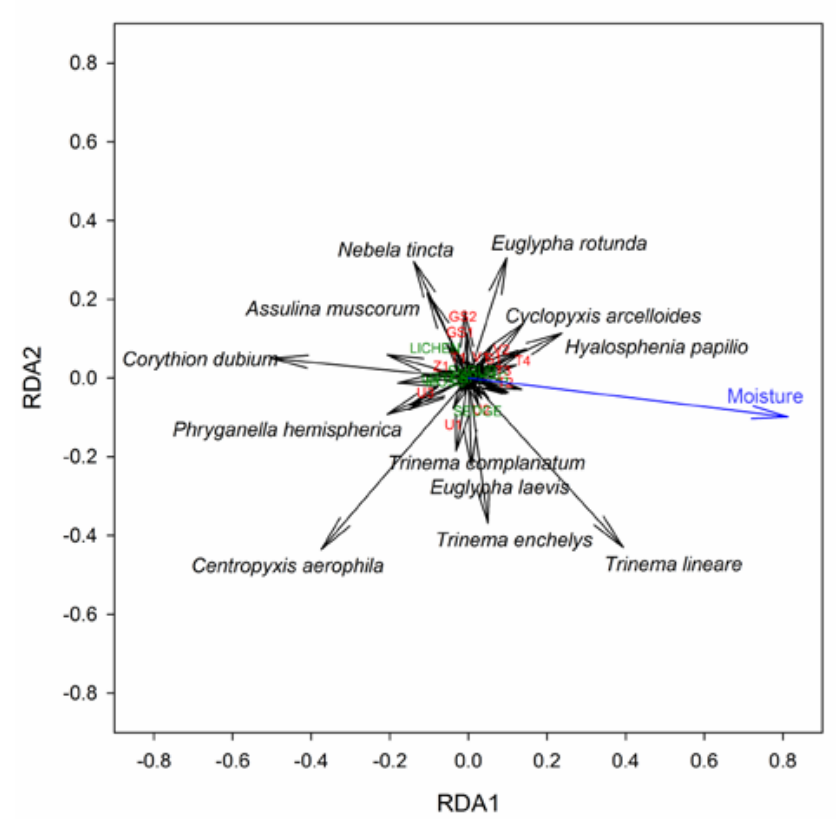

Fig. 5. Ordination biplot of RDA of testate amoeba species data showing vector for sample moisture content and centroids for sites (red) and vegetation types (green). Site codes: Gorno-Slinkino1: GS1, Gorno-Slinkino2: GS2, Surgut1: S1, Tobolsk1: T1, Tobolsk2: T2, Tobolsk3: T3, Tobolsk4: T4, Urengoi1: U1, Urengoi2: U2, Urengoi3: U3, Vinokurova1: V1, Vinokurova2: V2, Zapolyarnyi1: Z1. sociation, with more tests in wetter conditions and this association was significant for all of the most abundant taxa with the exception of $N$. tincta $(p=<0.05$; Fig. $6)$. However there was considerable variability in the form of this relationship. For several taxa (e.g. C. $d u$ bium, Phryganella hemisphaerica) there was variability in test concentration across the moisture gradient with a general trend to higher values in wetter samples. However for some other taxa (notably H. papilio and Euglypha tuberculata) the taxon was essentially only present in the very wettest sites. It therefore seems apparent that while most taxa were more abundant in wetter conditions, some taxa were only found in the wettest locations.

To address the diversity of the assemblage we calculated the Shannon Diversity Index. Shannon H' had a mean value of 2.0 which is similar to other testate amoeba studies. We found no correlation between Shannon H' and moisture content ( $r_{s}=-0.01, p=0.9$ ). We similarly found no significant difference in diversity between points with different vegetation classifications $\left(\chi^{2}(5)=6.3, p=0.28\right)$. We did find a difference between sampling sites but this was of relatively modest significance $\left(\chi^{2}(12)=24.4, p=0.02\right)$. The Shannon H'values of most sites were around the mean of 2.0 with the notable exception of the two Vinokurova sites which both had lower diversity of 1.4 and 1.6 respectively (Fig. 7). In post-hoc testing using the Nemenyi test the only significant pairwise difference in medians were between Vinkourova1 and both Tobolsk4 $(p=0.04)$ and Zapolyarnyil $(p=0.03)$.

\section{DISCUSSION}

In this study we present the largest TA dataset for Western Siberia and one of the larger individual contemporary datasets of peatland TA yet produced. Data such as those presented here are much needed for regional and supra-regional metaanalyses for addressing broad scale questions. The most abundant taxa encountered in the WSL have been observed in other studies of peatland TA and have widespread distribution across the Palearctic zone. Indeed several of these taxa (T. lineare, C. dubium) cannot be considered peatland specialists, being highly abundant in mineral soils. The community composition of our samples appears to strongly resemble those recorded in previous TA studies in the WSL (Kur'ina 2011, Kur'ina et al. 2010, Mazei and Chernyshov 2011, Rakhleeva 2002). Com- 

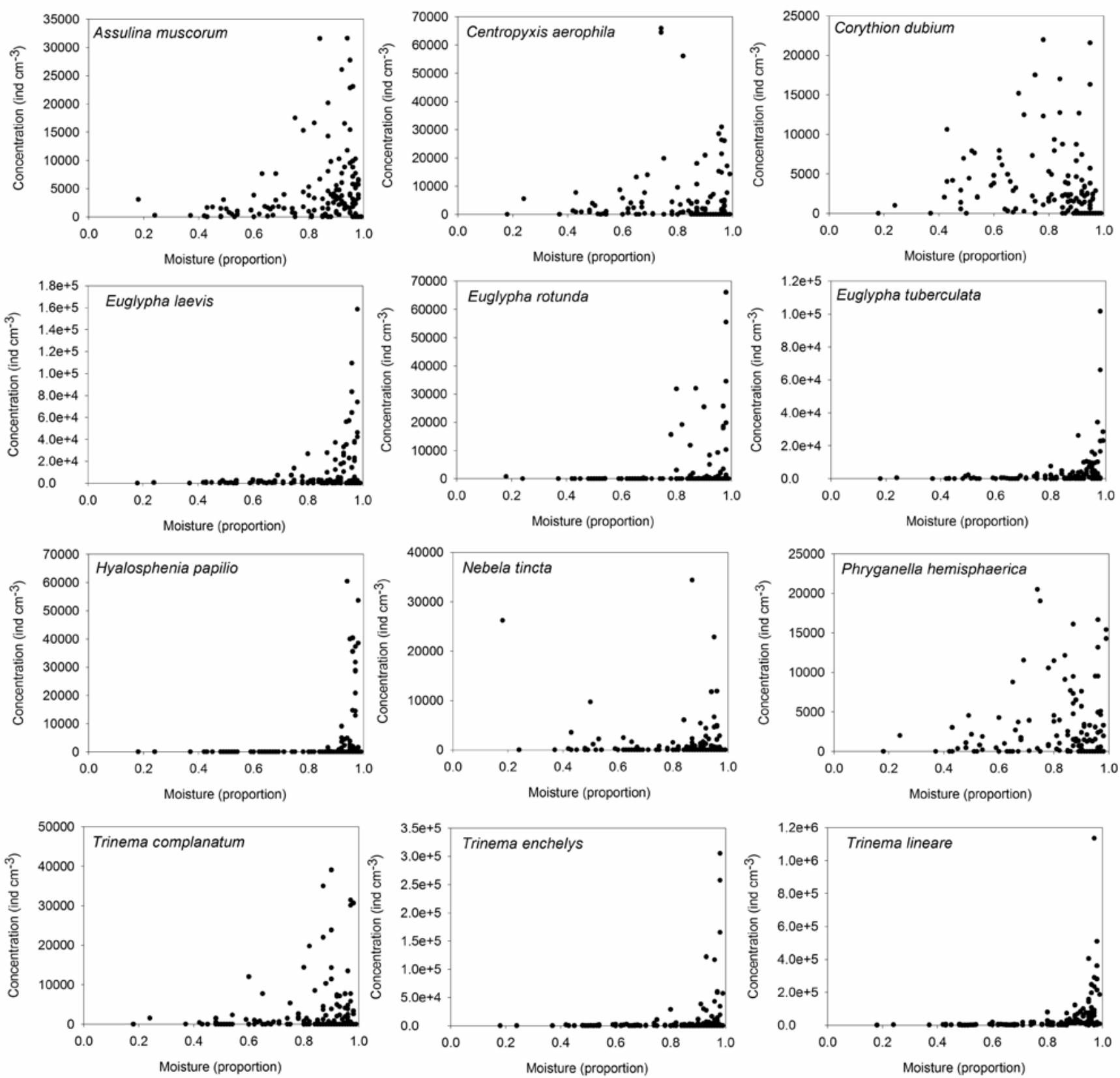

Fig. 6. Plots of taxon abundance versus moisture content for the twelve most abundant testate amoeba taxa. All taxa show a significant correlation with moisture (Spearman Rs, $\mathrm{P}<0.05$ ) with the exception of Nebela tincta.

pared to Western European datasets, test abundance values appeared higher than typical (e.g. Tolonen et al. 1992), however such comparisons are complicated by differing methodologies. Multivariate analysis in this study clearly demonstrates differing interpretations of TA community structure depending on measurements of relative abundance or absolute abundance (concentration). While concentrations have been calculated in many TA ecological studies, it has been frequent to only consider percentages in analysis (Charman and Warner 1992).

Our results demonstrate a significant role for surface moisture in structuring TA assemblages. The links between TA communities and 'wetness' are well-established in the literature (Smith et al. 2008). Numerous previous correlative studies have found strong links be- 


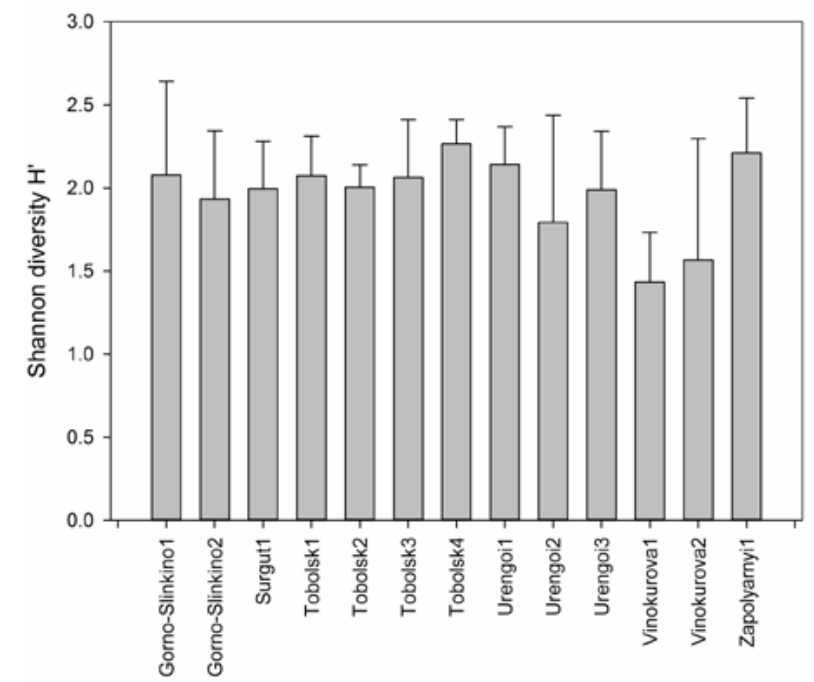

Fig. 7. Shannon diversity H' by site, showing mean and standard deviation.

tween TA communities and soil wetness, often explaining more species variance than other variables (Payne et al. 2012a). A substantial majority of these studies have considered water table depth (WTD) as the hydrological metric. Fewer studies have considered substrate moisture and many of these have found a substantially lower proportion of explained variance (Booth 2002, Charman 1997, Charman and Warner 1997, Woodland et al. 1998) although there are exceptions (Booth 2001, Charman and Blundell 2007). On theoretical grounds there are reasons for preferring either metric. WTD has the advantage of being a robust measure which is fieldrecordable and likely to be less prone to short-term variation. However it is also clear that water table depth per se cannot directly affect amoebae often living 10 $\mathrm{cm}$ or more above the water table. By contrast, surface moisture requires laboratory measurements, is more prone to experimental error due to changes in transit and is more likely to fluctuate on very short time-scales due to atmospheric conditions. However, an advantage of surface moisture is that the link between the measurement and the conditions which actually affect the amoebae is much clearer as it directly reflects the zone where amoebae live. While WTD has assumed the status of the 'standard' measure of wetness in testate amoeba palaeoecology and ecology, our results demonstrate that quantification of substrate moisture content has the potential to explain significant variance in TA assemblages. We suggest that moisture content remains a useful alternative to WTD.
The preferences of many individual TA species for moisture content have been long known (Jung 1936). For instance, the preferences of Hyalosphenia papilio for wetter conditions and the greater relative abundance of Assulina muscorum and Corythion dubium in drier conditions are well-established. However, the results for Trinema lineare here showing tendency towards wetter conditions are somewhat surprising. While many studies have suggested dry optima for this taxon (or groups containing this taxon) (Amesbury et al. 2016), our results suggest very high abundance in many samples with high moisture content. It is plausible that this may relate to pseudocryptic diversity in this diminutive taxon which is difficult to observe in detail at standard magnifications. Differences may also be due to our focus on moisture content rather than WTD.

Site identity explained the largest proportion of variance in the ordinations. There could be numerous reasons for this, encompassing factors such as climate, vegetation and hydrological regime. With only thirteen peatlands sampled our study has insufficient site-level replication to allow us to robustly investigate the underlying reasons for this result. Further data collection and the integration of existing datasets would be desirable to investigate these broader landscape-scale factors.

We also found significant variance was explained by vegetation, despite the very broad vegetation classes we assigned. Vegetation is likely to influence amoebae in numerous ways by determining the physical and chemical structure of their environment and by hosting microorganisms which may interact with amoebae (Vohník et al. 2011). However, a large proportion of the total variance in the testate amoeba assemblage was not explained by any of the recorded variables. There are several factors which are known to influence TA that were not quantified in this study, including $\mathrm{pH}$ (for example, Payne et al. 2006), nutrient status (Lamentowicz et al. 2013) and atmospheric pollution (Payne et al. 2012b). However it is also frequently the case that the majority of variance is unexplained in studies of this nature, pointing to controls on peatland TA which are not yet fully understood.

Two key features of our dataset are of particular interest. One is the relatively low abundance or absence of taxa which are frequent and abundant in peatland TA studies from western Europe and north America including Archerella flavum, Hyalosphenia papilio and Heleopera species. The second feature is the relatively small proportion of variance explained by sample moisture, less than $5 \%$. It is interesting to note that these re- 
sults parallel those from peatlands further south in Asia. In peatlands of China many of these 'typical' peatland taxa seem to be rare and studies which have used ordination to test links with hydrology have often found relatively low explained variance (Qin et al. 2012, 2013; Qin and Xie 2011). It is interesting to speculate whether there are systematic differences in both TA communities and their environmental controls (such as latitudinal effects, geographic isolation or niche-driven community patterns) in Asia than Europe and North America.

\section{APPLICATIONS}

One clear rationale for studying the modern ecology of TA in this region is as comparative data for palaeoecological studies. There is increasing interest in the use of palaeoecological records to investigate the stability of the global peatland carbon store to climate change and TA are considered useful palaeoclimate proxies. As the largest single peatland area, the WSL is a key location for this research but such studies are only beginning to be undertaken (Lamentowicz et al. 2015). Our results show links between TA and moisture, demonstrating the potential of this approach, and will be useful as comparative data. Another important potential application for TA in this region is monitoring the impacts of fossil fuel extraction in terms of habitat disturbance and pollution (Kartashev 2008). Currently large-scale exploitation of oil and gas resources is underway across the WSL with extraction sites frequently located in or adjacent to peatland landscapes. The application of TA to study environmental impacts of oil and gas extraction in western Siberian peatlands could be an interesting research direction. A large number of recent studies have investigated the potential for TA as bioindicators of a variety of aspects of mining impacts with generally promising results (Nasser et al. 2016, Neville et al. 2014, Patterson et al. 2013). TA bioindicators have the potential advantages of being functionally significant, showing rapid response to environmental impacts and being comparatively easy to study (Payne 2013).

Acknowledgements. The work was supported by the Russian Science Foundation, grant 14-14-00891 to YuM (data analysis) and Russian Foundation for Basic Research, grant 16-04-00803 to YuM (microscopic analysis). UK-Russia research cooperation was supported by a Royal Society International Exchange grant to RJP (IE150173).

Author contributions: YuM conceived, led and planned the study and secured funding. YuM and SB conducted fieldwork, VCh and NM conducted microscopy. RJP conducted data analysis with assistance from AC. RJP wrote the first draft of the paper. All authors commented on the draft and provided interpretation.

\section{REFERENCES}

Amesbury M. J., Mallon G., Charman D. J., Hughes P. D. M., Booth R. K., Daley T. J., Garneau M. (2013) Statistical testing of a new testate amoeba-based transfer function for water-table depth reconstruction on ombrotrophic peatlands in north-eastern Canada and Maine, United States. J. Quaternary Sci. 28: 27-39

Amesbury M. J., Swindles G. T., Bobrov A., Charman D. J., Holden J., Lamentowicz M., Mallon G., Mazei Y., Mitchell E. A., Payne R. J. (2016) Development of a new pan-European testate amoeba transfer function for reconstructing peatland palaeohydrology. Quaternary Sci. Rev. 152: 132-151

Avel E., Pensa M. (2013) Preparation of testate amoebae samples affects water table depth reconstructions in peatland palaeoecological studies. Estonian J. Earth Sci. 62: 113-119

Bamforth S. S. (2008) Protozoa of biological soil crusts of a cool desert in Utah. J. Arid Environ. 72: 722-729

Bobrov A. (2003) Historical dynamics of lake and bog ecosystems and succession of testate amoebae (Testacea, Protozoa). Zoologicheskiy Zhurnal. 82: 215-223

Bobrov A., Qin Y., Wilkinson D. M. (2015) Latitudinal diversity gradients in free-living microorganisms-Hoogenraadia a key genus in testate amoebae biogeography. Acta Protozool. 54: 1

Bokova U., Babenko A., Temnikova I. (2015) Ecological peculiarities of the testate amoebae population in the Middle $\mathrm{Ob}$ flood plain. Int. J. Environ Studies. 72: 406-414

Booth R. K. (2001) Ecology of testate amoebae (Protozoa) in two Lake Superior coastal wetlands: implications for paleoecology and environmental monitoring. Wetlands. 21: 564-576

Booth R. K. (2002) Testate amoebae as paleoindicators of surfacemoisture changes on Michigan peatlands: modern ecology and hydrological calibration. J. Paleolimnol. 28: 329-348

Booth R. K. (2008) Testate amoebae as proxies for mean annual water-table depth in Sphagnum-dominated peatlands of North America. J. Quaternary Sci. 23: 43-57

Bray J. R., Curtis J. T. (1957) An ordination of the upland forest communities of southern Wisconsin. Ecol. Monogr. 27: 325349

Charman D. J. (1997) Modelling hydrological relationships of testate amoebae (Protozoa: Rhizopoda) on New Zealand peatlands. J. R. Soc. N. Z. 27: 465-483

Charman D. J. (1999) Testate amoebae and the fossil record: issues in biodiversity. J. Biogeogr. 26: 89-96

Charman D. J., Blundell A. (2007) A new European testate amoebae transfer function for palaeohydrological reconstruction on ombrotrophic peatlands. J. Quaternary Sci. 22: 209-221

Charman D. J., Warner B. G. (1992) Relationship between testate amoebae (Protozoa: Rhizopoda) and microenvironmental parameters on a forested peatland in northeastern Ontario. Can. J. Zool. 70: 2474-2482

Charman D. J., Warner B. G. (1997) Ecology of testate amoebae (Protozoa: Rhizopoda) in oceanic peatlands in Newfoundland, Canada: modelling hydrological relationships for palaeoenvironmental reconstruction. Ecoscience. 4: 555-562

Clarke K. R. (1993) Non-parametric multivariate analyses of changes in community structure. Aus. J. Ecol. 18: 117-143. 
DeJong T. (1975) A comparison of three diversity indices based on their components of richness and evenness. Oikos. 26: 222-227

Gilbert D., Amblard C., Bourdier G., Francez A. J. (1998a) Shortterm effect of nitrogen enrichment on the microbial communities of a peatland, in: Amiard J. C., Le Rouzic B., Berthet B., Bertru G. (Eds.), Oceans, Rivers and Lakes: Energy and Substance Transfers at Interfaces: Proceedings of the Third International Joint Conference on Limnology and Oceanography held in Nantes, France, October 1996. Springer Netherlands, Dordrecht, pp. 111-119

Gilbert D., Amblard C., Bourdier G., Francez A. J. (1998b) The microbial loop at the surface of a peatland: structure, function, and impact of nutrient input. Microb. Ecol. 35: 83-93

International Peat Society (2017) Global Peat Resources by Country. http://www.peatsociety.org/peatlands-and-peat/global-peatresources-country (accessed 1/5/17)

Jassey V. E. J., Shimano S., Dupuy C., Toussaint M. L., Gilbert D. (2012) Characterizing the feeding habits of the testate amoebae Hyalosphenia papilio and Nebela tincta along a narrow "fenbog" gradient using digestive vacuole content and $13 \mathrm{C}$ and $15 \mathrm{~N}$ isotopic analyses. Protist. 163: 451-464

Jung W. (1936) Thecamoeben ursprünglicher lebender deutscher Hochmoore. Abh. Landesmus Westfalen. 7: 3-87

Kartashev A. G., Smolina T. V. (2008) Impact of oil on soil testate amoebae (Arcellinida, Euglyphida) in a field experiment. Zoologicheskiy Zhurnal. 87: 1027-1033

Kur'ina I. V. (2011) Ecology of testate amoebae as hydrological regime indicators in oligotrophic peatlands in the southern taiga of Western Siberia. Izvesti Penzenskogo Gosudarstvennogo Pedagogicheskogo Universiteta. 25: 368-375

Kur'ina I. V., Preis Y. I., Bobrov A. (2010) Testate amoebae inhabiting middle taiga bogs in Western Siberia. Biol. Bull. 37: 357-362

Lamentowicz M., Lamentowicz Ł., Payne R. J. (2013) Towards quantitative reconstruction of peatland nutrient status from fens. Holocene. 23: 1661-1665

Lamentowicz M., Słowiński M., Marcisz K., Zielińska M., Kaliszan K., Lapshina E., Gilbert D., Buttler A., FiałkiewiczKozieł B., Jassey V. E. (2015) Hydrological dynamics and fire history of the last 1300 years in western Siberia reconstructed from a high-resolution, ombrotrophic peat archive. Quaternary Res. 84: 312-325

Lara E., Roussel-Delif L., Fournier B., Wilkinson D. M., Mitchell E. A. (2016) Soil microorganisms behave like macroscopic organisms: patterns in the global distribution of soil euglyphid testate amoebae. J. Biogeogr. 43: 520-532

Legendre P., Gallagher E. D. (2001) Ecologically meaningful transformations for ordination of species data. Oecologia. 129: 271-280

Mazei Y., Belyakova O., Coppellotti O., Payne R. J. (2016) Testate amoeba communities of epilithic mosses and lichens: new data from Russia, Switzerland and Italy. Acta Protozool. 55: 51-59

Mazei Y., Bubnova O. A. (2007a) Species composition and structure of testate amoebae community in a Sphagnum bog at the initial stage of its formation. Biol. Bull. 34: 619-628

Mazei Y., Chernyshov V., Tsyganov A. N., Payne R. J. (2015) Testing the Effect of Refrigerated Storage on Testate Amoeba Samples. Microb. Ecol. 70: 861-864

Mazei Y., Tsyganov A. N. (2006) Freshwater testate amoebae. KMK: Moscow

Mazei Y., Tsyganov A. N. (2007b) Species composition, spatial distribution and seasonal dynamics of testate amoebae community in a Sphagnum bog (Middle Volga region, Russia). Protistol. 5: 156-206

Mazei Y., Tsyganov A. N., Bubnova O. A. (2007c) Structure of a community of testate amoebae in a Sphagnum dominated bog in upper Sura flow (Middle Volga territory). Biol. Bull. 34: 382-394

Mazei Y. A., Blinokhvatova Y. V., Embulaeva E. A. (2011) Specific features of the microspatial distribution of soil testate amoebae in the forests of the Middle Volga region. Arid. Ecosystems. 1: $46-52$

Mazei Y. A., Chernyshov V. (2011) Testate amoebae communities in the southern tundra and forest-tundra of Western Siberia. Biol. Bull. 38: 789-796

Mitchell E. A. D., Charman D. J., Warner B. G. (2008) Testate amoebae analysis in ecological and paleoecological studies of wetlands: past, present and future. Biodivers. Conserv. 17: 2115-2137

Nasser N. A., Patterson R. T., Roe H. M., Galloway J. M., Falck H., Palmer M. J., Spence C., Sanei H., Macumber A. L., Neville L. A. (2016) Lacustrine Arcellinina (Testate Amoebae) as bioindicators of arsenic contamination. Microb. Ecol. 72: 130-149

Neville L. A., Patterson R. T., Gammon P., Macumber A. L. (2014) Relationship between ecological indicators (Arcellacea), total mercury concentrations and grain size in lakes within the Athabasca oil sands region, Alberta. Environ. Earth Sci. 72: 577-588

Oksanen J., Kindt R., Legendre P., O'Hara B., Stevens M. H. H., Oksanen M. J., Suggests M. (2007) The vegan package. https:// cran.r-project.org/web/packages/vegan/index.html

Patterson R. T., Lamoureux E. D., Neville L. A., Macumber A. L. (2013) Arcellacea (testate lobose amoebae) as $\mathrm{pH}$ indicators in a pyrite mine-acidified lake, Northeastern Ontario, Canada. $M i$ crob. Ecol. 65: 541-554

Payne R. (2009) The standard preparation method for testate amoebae leads to selective loss of the smallest taxa. Quaternary Newsl. 119: 16-20

Payne R., Telford R., Blackford J., Blundell A., Booth R., Charman D., Lamentowicz Ł., Lamentowicz M., Mitchell E., Potts G., Swindles G., Warner B. W. W. (2012a) Testing peatland testate amoeba transfer functions: appropriate methods for clustered training-sets. Holocene. 22: 819-825

Payne R. J. (2013) Seven reasons why protists make useful bioindicators. Acta Protozool. 52: 105

Payne R. J., Babeshko K. V., van Bellen S., Blackford J. J., Booth R. K., Charman D. J., Ellershaw M. R., Gilbert D., Hughes P. D., Jassey V. E. (2016) Significance testing testate amoeba water table reconstructions. Quaternary Sci. Rev. 138: 131-135

Payne R. J., Kishaba K., Blackford J. J., Mitchell E. A. D. (2006) Ecology of testate amoebae (Protista) in south-central Alaska peatlands: building transfer-function models for palaeoenvironmental studies. Holocene. 16: 403-414

Payne R. J., Mitchell E. A. D. (2009) How many is enough? Determining optimal count totals for ecological and palaeoecological studies of testate amoebae. J. Paleolimnol. 42: 483-495

Payne R. J., Mitchell E. A. D., Nguyen-Viet H., Gilbert D. (2012b) Can pollution bias peatland paleoclimate reconstruction? Quaternary Res. 78: 170-173

Qin Y., Mitchell E. A., Lamentowicz M., Payne R. J., Lara E., Gu Y., Huang X., Wang H. (2013) Ecology of testate amoebae in peatlands of central China and development of a transfer function for paleohydrological reconstruction. J. Paleolimnol. 50: $319-330$ 
Qin Y., Payne R. J., Gu Y., Huang X., Wang H. (2012) Ecology of testate amoebae in Dajiuhu peatland of Shennongjia Mountains, China, in relation to hydrology. Frontiers Earth Sci. 6: 57-65

Qin Y., Xie S. (2011) Moss-dwelling testate amoebae and their community in Dajiuhu peatland of Shennongjia Mountains, China. J. Freshwater Ecol. 26: 3-9

R Development Core Team (2014) R: A language and environment for statistical computing. R foundation for Statistical Computing

Rakhleeva A. (2002) Testaceans (Testacea, Protozoa) of Taiga Soils in Western Siberia (Surgut Polesye). Biol. Bull. 29: 618-627

Ripley B. (2016) Package 'MASS'. University of Oxford. https:// cran.r-project.org/web/packages/MASS/index.html

Sheng Y., Smith L. C., MacDonald G. M., Kremenetski K. V., Frey K. E., Velichko A. A., Lee M., Beilman D. W., Dubinin P. (2004) A high-resolution GIS-based inventory of the west Siberian peat carbon pool. Glob. Biogeochem. Cy. 18: GB3004
Smith H. G., Bobrov A., Lara E. (2008) Diversity and biogeography of testate amoebae. Biodivers. Conserv. 17: 329-343

Tolonen K., Warner B. G., Vasander H. (1992) Ecology of testaceans (Protozoa: Rhizopoda) in mires in southern Finland: I. Autecology. Archiv. für Protistenk. 142: 119-138

Tsyganov A. N., Mityaeva O. A., Mazei Y. A., Payne R. J. (2016) Testate amoeba transfer function performance along localised hydrological gradients. Eur. J. Protistol. 55: 141-151

Vohník M., Burdíková Z., Vyhnal A., Koukol O. (2011) Interactions between testate amoebae and saprotrophic microfungi in a Scots pine litter microcosm. Microb. Ecol. 61: 660-668

Woodland W. A., Charman D. J., Sims P. C. (1998) Quantitative estimates of water tables and soil moisture in Holocene peatlands from testate amoebae. Holocene. 8: 261-273

Received on $1^{\text {st }}$ March, 2017; revised on $25^{\text {th }}$ May, 2017; accepted on $5^{\text {th }}$ June, 2017

\section{APPENDIX 1}

Full species list: Arcella arenaria Arcella arenaria compressa Arcella arenaria sphagnicolla Arcella catinus Arcella discoides Arcella gibbosa Arcella hemisphaerica Arcella megastoma Arcella rotundata Archerella flavum Armipyxis discoides Assulina muscorum Assulina seminulum Awerintzewia cyclostoma Bullinularia indica Centropyxis aculeata Centropyxis aerophila Centropyxis aerophila sphagnicola Centropyxis cassis Centropyxis ecornis Centropyxis gibba Centropyxis orbicularis Centropyxis platystoma Centropyxis sylvatica Centropyxis sylvatica minor Corythion dubium Corythion orbicularis Cryptodifflugia oviformis Cyclopyxis arcelloides
Cyclopyxis eurystoma Cyclopyxis kahli Difflugia bacillariarum Difflugia bacillifera Difflugia elegans Difflugia globulosa Difflugia penardi Ellipsopyxis sp. Euglypha acanthophora Euglypha capsiosa Euglypha ciliata Euglypha ciliata glabra Euglypha compressa Euglypha compressa glabra Euglypha cristata Euglypha cristata decora Euglypha denticulata Euglypha laevis Euglypha rotunda Euglypha scutigera Euglypha simplex Euglypha strigosa Euglypha strigosa glabra Euglypha tuberculata Gibbocarina galeata Heleopera sphagni Hyalosphenia elegans Hyalosphenia papilio Lesquereusia epistomium Nebela bohemica

\author{
Nebela collaris \\ Nebela longicollis \\ Nebela militaris \\ Nebela parvula \\ Nebela tincta \\ Netzelia oviformis \\ Netzelia wailesi \\ Padaungiella wailesi \\ Paraqudrula irregularis \\ Phryganella acropodia \\ Phryganella hemisphaerica \\ Physochilla griseola \\ Physochilla tenella \\ Placocista spinosa \\ Plagiopyxis labiata \\ Planocarina carinata \\ Planocarina marginata \\ Sphenoderia fissirostris \\ Sphenoderia lenta \\ Tracheleuglypha dentata \\ Trigonopyxis arcula \\ Trigonopyxis arcula major \\ Trigonopyxis minuta \\ Trinema complanatum \\ Trinema complanatum elongata \\ Trinema enchelys \\ Trinema grandis \\ Trinema lineare \\ Trinema lineare truncatum \\ Trinema penardi
}

